Article

\title{
Self-Aligned Hierarchical ZnO Nanorod/NiO Nanosheet Arrays for High Photon Extraction Efficiency of GaN-Based Photonic Emitter
}

\author{
Won-Seok Lee ${ }^{1} \mathbb{D}$, Soon-Hwan Kwon ${ }^{1}$, Hee-Jung Choi ${ }^{1}$, Kwang-Gyun Im ${ }^{2}$, Hannah Lee ${ }^{1}$, \\ Semi Oh ${ }^{3, *}$ and Kyoung-Kook Kim ${ }^{1,2, *}$ \\ 1 Department of Advanced Convergence Technology, Research Institute of Advanced Convergence \\ Technology, Korea Polytechnic University, Gyeonggi-do 15073, Korea; dldnjstjr37@kpu.ac.kr (W.-S.L.); \\ canwkd21@kpu.ac.kr (S.-H.K.); gmlwjd0889@kpu.ac.kr (H.-J.C.); leehn331@kpu.ac.kr (H.L.) \\ 2 Department of Nano \& Semiconductor Engineering, Korea Polytechnic University, \\ Gyeonggi-do 15073, Korea; rhkdrbs87@kpu.ac.kr \\ 3 Department of Electrical Engineering and Computer Science, University of Michigan, \\ Ann Arbor, MI 48109, USA \\ * Correspondence: semio@umich.edu (S.O.); kim.kk@kpu.ac.kr (K.-K.K.)
}

Received: 29 February 2020; Accepted: 25 March 2020; Published: 26 March 2020

\begin{abstract}
Advancements in nanotechnology have facilitated the increased use of $\mathrm{ZnO}$ nanostructures. In particular, hierarchical and core-shell nanostructures, providing a graded refractive index change, have recently been applied to enhance the photon extraction efficiency of photonic emitters. In this study, we demonstrate self-aligned hierarchical $\mathrm{ZnO}$ nanorod (ZNR)/ $\mathrm{NiO}$ nanosheet arrays on a conventional photonic emitter (C-emitter) with a wavelength of $430 \mathrm{~nm}$. These hierarchical nanostructures were synthesized through a two-step hydrothermal process at low temperature, and their optical output power was approximately 17\% higher than that of ZNR arrays on a C-emitter and two times higher than that of a C-emitter. These results are due to the graded index change in refractive index from the GaN layer inside the device toward the outside as well as decreases in the total internal reflection and Fresnel reflection of the photonic emitter.
\end{abstract}

Keywords: self-align; hierarchical nanostructures; $\mathrm{ZnO}$ nanorod/NiO nanosheet; photon extraction efficiency; photonic emitter

\section{Introduction}

The advancements in nanotechnology have facilitated the increased use of $\mathrm{ZnO}$ nanostructures that, for example, are widely utilized in photonic devices because of their peculiar chemical and physical properties [1-5]. Different dimensions from zero to three-dimensional ZnO nanostructures have been synthesized using various precursors. These nanostructures are particularly important for realizing many applications, such as electronic devices, catalysis, and biomedical and sensing usage, especially, visible ultraviolet optical devices [6-11].

Especially, one-dimensional (1D) ZnO nanostructures can be widely used in photonic emitters and photodetectors because of their easy refractive index control, transparency in the visible light range, high photoreactivity, and light waveguide properties [12-14]. According to effective medium approximation (EMA), the effective refractive index ( $\left.n_{\mathrm{eff}}\right)$ of $\mathrm{ZnO}$ ( $\mathrm{ZnO}$ film: $n=2.1$ at visible wavelengths) decreases when it is converted into nanostructures [15-18].

For achieving a higher photon extraction efficiency (PEE), a material with a refractive index lower than that of ITO (2.1 at visible wavelengths) is required to reduce the total internal reflection (TIR) in a conventional photonic emitter (C-emitter) and increase its outward light emission, that is, in air 
$(n=1)$. Although the $\mathrm{ZnO}$ nanostructures can partially mitigate the abrupt change of refractive indices between $p$-type GaN and air, TIR and Fresnel reflection losses occur at the ZnO/air interface [19,20].

Therefore, alternative materials and structures are required for effective photon extraction from a GaN-based photonic emitter to the outside by matching the refractive indices and for realizing exceptional photon emission from surface nanostructures.

Recently, hierarchical and core-shell nanostructures that provide graded refractive index changes have been applied to achieve high PEE in photonic emitters [11,21-25]. However, for the realization of hierarchical nanostructures, a separate seed layer deposition, high cost vacuum systems, and complicate fabrication processes are required $[24,26,27]$. To solve these problems, rapid manufacturing techniques are required.

In this study, we demonstrate self-aligned hierarchical $\mathrm{ZnO}$ nanorod (ZNR)/NiO nanosheet (NNS) arrays to realize the high PEE of a GaN-based C-emitter. These hierarchical nanostructures are synthesized through a two-step hydrothermal process at low temperatures. The optical output power of the as-obtained C-emitter is approximately $17 \%$ and it is two times higher than that of the C-emitter with ZNRs and C-emitter without nanostructures. This increase can be ascribed to a graded change in the refractive index between the GaN layer and the device exterior, as well as a decrease in the TIR and Fresnel reflection of the photonic emitter.

\section{Materials and Methods}

\subsection{Device Fabrication}

Epilayers were grown on a sapphire substrate by metal-organic chemical vapor deposition. The photonic emitter (chip size: $350 \times 350 \mu \mathrm{m}^{2}$ ) with a $430 \mathrm{~nm}$ wavelength consisted of a $0.12 \mu \mathrm{m}$-thick p-type GaN:Mg $\left(n=3 \times 10^{17} \mathrm{~cm}^{-3}\right)$ layer, a $0.08 \mu \mathrm{m}$ active layer, a $2.5 \mu \mathrm{m}$-thick undoped GaN layer, and a $4.0 \mu \mathrm{m}$-thick $n$-type GaN:Si $\left(n=5 \times 10^{18} \mathrm{~cm}^{-3}\right)$ layer on the sapphire substrate. All emitter samples were ultrasonically degreased with acetone, methanol, deionized (DI) water, and a mixture of sulfuric acid and hydrogen peroxide (3:1) for $5 \mathrm{~min}$ in each step to remove organic and inorganic contaminants. Then, to fabricate the $n$-electrode, the epilayers were partially etched until the $n$-type $\mathrm{GaN}$ layer was exposed. The $200 \mathrm{~nm}$ thick ITO layer was deposited using an electron-beam evaporator on the remaining parts of the $p$-type GaN layer and annealed at $600{ }^{\circ} \mathrm{C}$ in $\mathrm{O}_{2}$ atmosphere for $1 \mathrm{~min}$ using the rapid thermal annealing. The Ti/Al $(50 / 200 \mathrm{~nm})$ layers were deposited as an $n$-electrode. Finally, the $\mathrm{Cr} / \mathrm{Al}(30 / 200 \mathrm{~nm})$ layers were deposited on the $p$ - and $n$-electrodes and annealed at $300{ }^{\circ} \mathrm{C}$ for $1 \mathrm{~min}$.

\subsection{ZNRs Synthesis}

A $\mathrm{ZnO}$ seed layer was formed on the selectively deposited ITO by a simple dipping process as follows. First, $105 \mathrm{mM}$ zinc acetate $\left(\mathrm{Zn}\left(\mathrm{C}_{2} \mathrm{H}_{3} \mathrm{O}_{2}\right)_{2}\right)$ dissolved in DI water was synthesized at $90^{\circ} \mathrm{C}$ for $1 \mathrm{~h}$. Then, ZNRs were grown using $37.5 \mathrm{mM}$ zinc nitrate hexahydrate $\left(\mathrm{Zn}\left(\mathrm{NO}_{3}\right)_{2}{ }^{*} 6 \mathrm{H}_{2} \mathrm{O}\right)$ and $75 \mathrm{mM}$ hexamethylenetetramine $\left(\mathrm{C}_{6} \mathrm{H}_{12} \mathrm{~N}_{4}\right)$ dissolved in $300 \mathrm{~mL}$ of DI water at $90^{\circ} \mathrm{C}$ for $6 \mathrm{~h}$.

\subsection{Hierarchical ZNR/NNS Arrays Synthesis}

Nickel nitrate hexahydrate $\left(\mathrm{Ni}\left(\mathrm{NO}_{3}\right)_{2}{ }^{*} 6 \mathrm{H}_{2} \mathrm{O}\right)(10.4 \mathrm{mg})$ was dissolved in DI water $(50 \mathrm{~mL})$ and stirred for $30 \mathrm{~min}$. Then, this solution was used to synthesis NNSs on the ZNRs at $90^{\circ} \mathrm{C}$ for $1 \mathrm{~h}$.

\subsection{Characterization}

The structural shapes of the self-aligned ZNRs and hierarchical ZNR/NNS arrays were observed using a field emission-scanning electron microscope (FESEM, Hitachi S4300, Tokyo, Japan), and the hierarchical nanostructures were analyzed using an energy-dispersive spectroscopy (EDS) mounted on the FESEM. The electrical and optical properties were measured using a parameter analyzer (Keithley 2400, Tektronix, Beaverton, OR, USA), an optical power meter (Newport 1830C, Irvine, CA, USA), and 
an optical microscope (Velcam CVC5220, Chun Shin Electronics Inc., Taipei, Taiwan). Finite-difference time-domain (FDTD) simulation was conducted to compare the light output of the fabricated photonic emitter with that of a C-emitter.

\section{Results and Discussion}

The schematic diagram of the ZNR/NNS arrays synthesis on the C-emitter by following the proposed experimental procedures is shown in Figure 1.

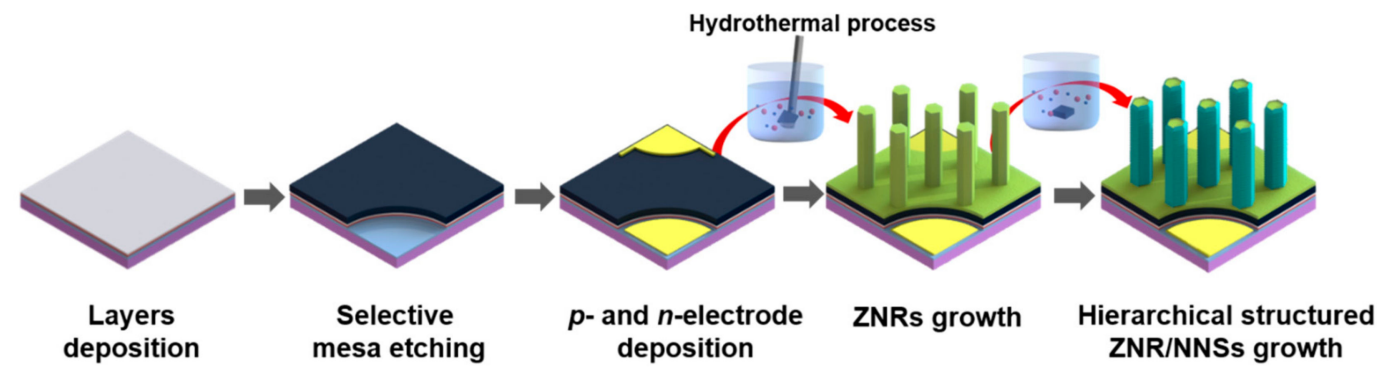

Figure 1. Fabrication process of $\mathrm{C}$-emitter with hierarchical $\mathrm{ZnO}$ nanorod $(\mathrm{ZNR}) / \mathrm{NiO}$ nanosheet (NNS) arrays.

The FESEM image in Figure 2a shows the ZNRs with an average diameter and length of $300 \mathrm{~nm}$ and $3.5 \mu \mathrm{m}$, respectively. To understand the growth mechanism of the ZNR/NNS arrays, the study of the morphology evolution of hierarchical ZNR/NNS arrays during the reaction time has been carried out, as shown in Figure 2b-e.
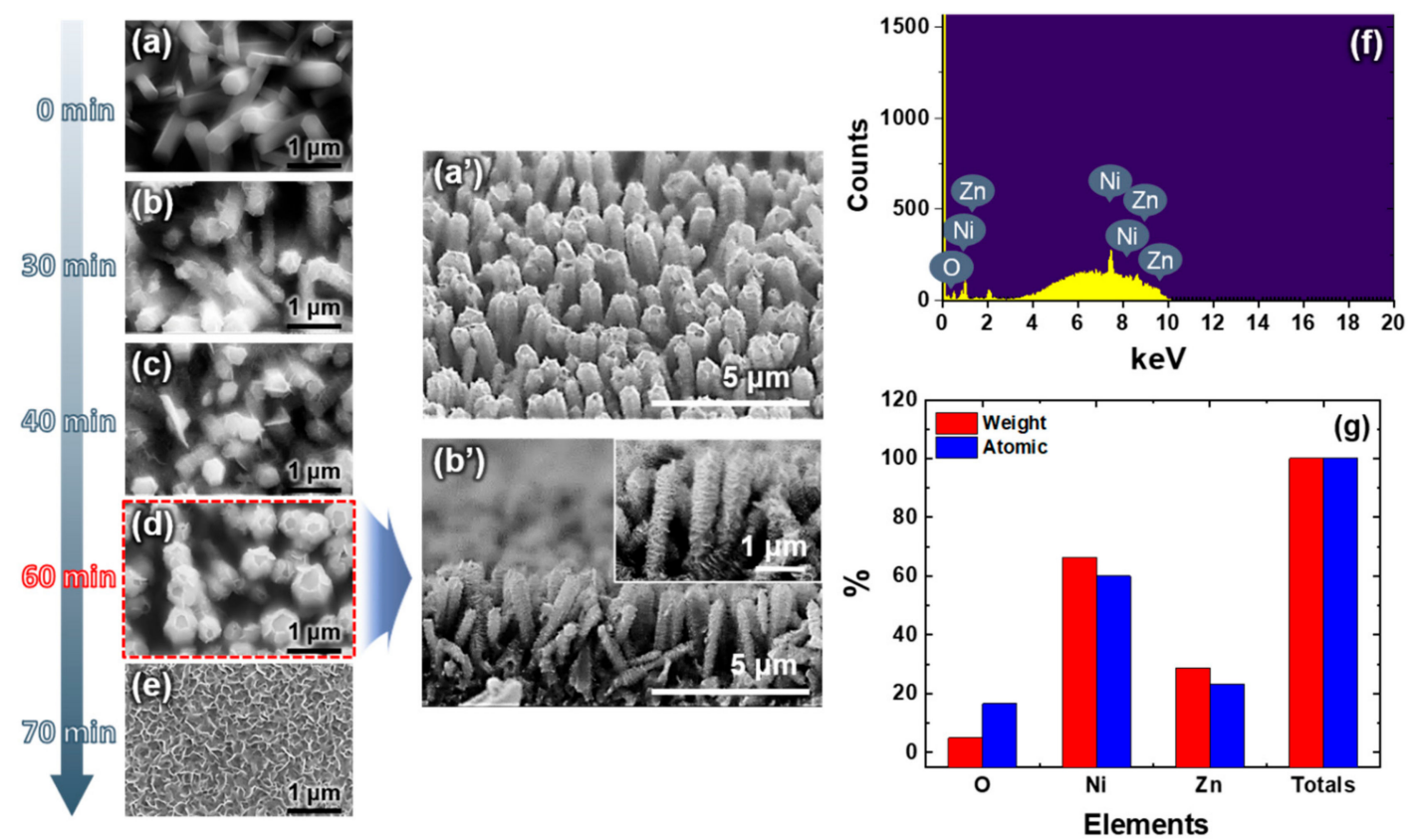

Figure 2. Field emission-scanning electron microscope (FESEM) images of (a) ZNRs and (b-e) hierarchical ZNR/NNS arrays grown for different times; ( $\left.\mathbf{a}^{\prime}\right)$ tilt and $\left(\mathbf{b}^{\prime}\right)$ cross-sectional FESEM images of (d). (f) an energy-dispersive spectroscopy (EDS) and (g) atomic composition of the hierarchical ZNR/NNS arrays.

Since the system tends to minimize the overall surface energy, the ZNRs grew preferentially along the [0001] direction [28,29]. Then, Ni-based nanoparticles (NPs) nucleated on the surface of the ZNRs to form active sites, which minimized the interfacial energy barrier to promote the subsequent 
growth of Ni-based NPs. The merge of these NPs reduced the overall energy by decreasing the surface energy, which was beneficial for adjacent Ni-based NPs to spontaneously self-organize together. The self-organized NPs shared a common crystallographic orientation and formed a planar interface, as shown in Figure $2 \mathrm{~b}$. When the reaction proceeded for $30 \mathrm{~min}$, these NPs self-assembled to form large nanosheets (NSs) and finally generated the ZNR/NNS arrays. The above hypothesis is supported by examining the morphologies of NiO NSs at different growth stages by controlling the reaction time, as shown in Figure 2c,d. After exceeding a growth time of $60 \mathrm{~min}$, the NSs transformed into nanowalls (Figure 2e). Therefore, we selected $60 \mathrm{~min}$ as the optimum growth time for obtaining stable ZNR/NNS arrays. Figure $2 a^{\prime}, b^{\prime}$ show the tilted and cross-sectional FESEM images of the well-aligned NNS arrays grown for $60 \mathrm{~min}$. The results of an EDS analysis along with the atomic and weight values of the hierarchical ZNR/NNS arrays are shown in Figure 2f. The atomic contents of oxygen, nickel, and zinc were $16.6 \%, 60.09 \%$, and $23.32 \%$, respectively. The lower percentage of oxygen was ascribed to the fact that oxygen is relatively lighter than nickel and zinc [30]. These results confirmed the successful synthesis of the $\mathrm{ZnO}$ and $\mathrm{NiO}$ nanostructures.

To evaluate the properties of the fabricated photonic emitters, we measured their current-voltage curves and optical output intensity. Under the injection current of $20 \mathrm{~mA}$, the threshold voltages of the C-emitters without nanostructures, with ZNRs, and with hierarchical ZNR/NNS arrays ranged between 3.00 and $3.03 \mathrm{~V}$, as shown in Figure 3a. This indicates that the $\mathrm{ZnO}$ nanostructures did not affect the electrical properties of the emitters because they were grown using a low-temperature growth process. At the injection current of $100 \mathrm{~mA}$, the optical output power of the C-emitter with the hierarchical ZNR/NNS arrays was approximately 17\% higher than that of the device with ZNRs and two times higher than that of the photonic emitter without any nanostructures (Figure $3 b$ ). The inset emission images in Figure 3c-e show that the hierarchical ZNR/NNS arrays on the C-emitter are brighter than the other emitters at the injection current of $0.05 \mathrm{~mA}$. Compared to other studies on this topic, we realized the optimal refractive index between the ITO layer and air [31,32]. In addition, the higher optical output power can probably be attributed to the graded refractive index and the reduced Fresnel reflection.
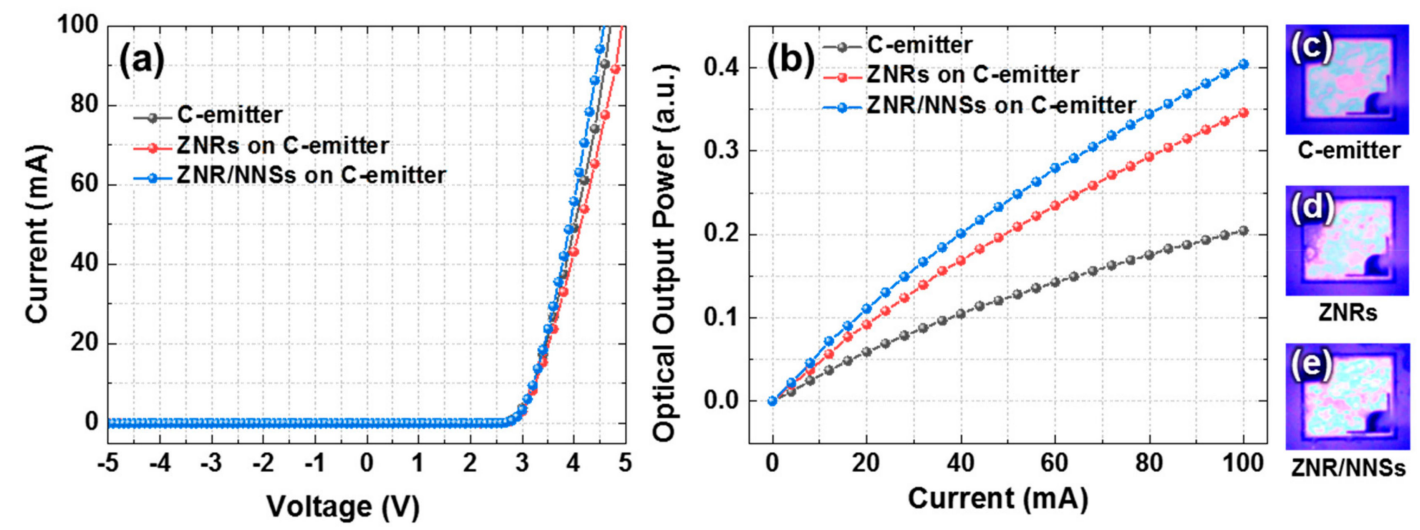

Figure 3. (a) Current-voltage curves, (b) current-optical output power curves, and (c-e) emission images (at an injection current of $0.05 \mathrm{~mA}$ ) of the C-emitter without nanostructures, with ZNRs, and with hierarchical ZNR/NNS arrays.

Then, we performed FDTD simulations to compare the three C-emitter types. Figure $4 a, b$ show schematic diagrams of the overall structures of the devices with the ZNR and the hierarchical ZNR/NNS. 

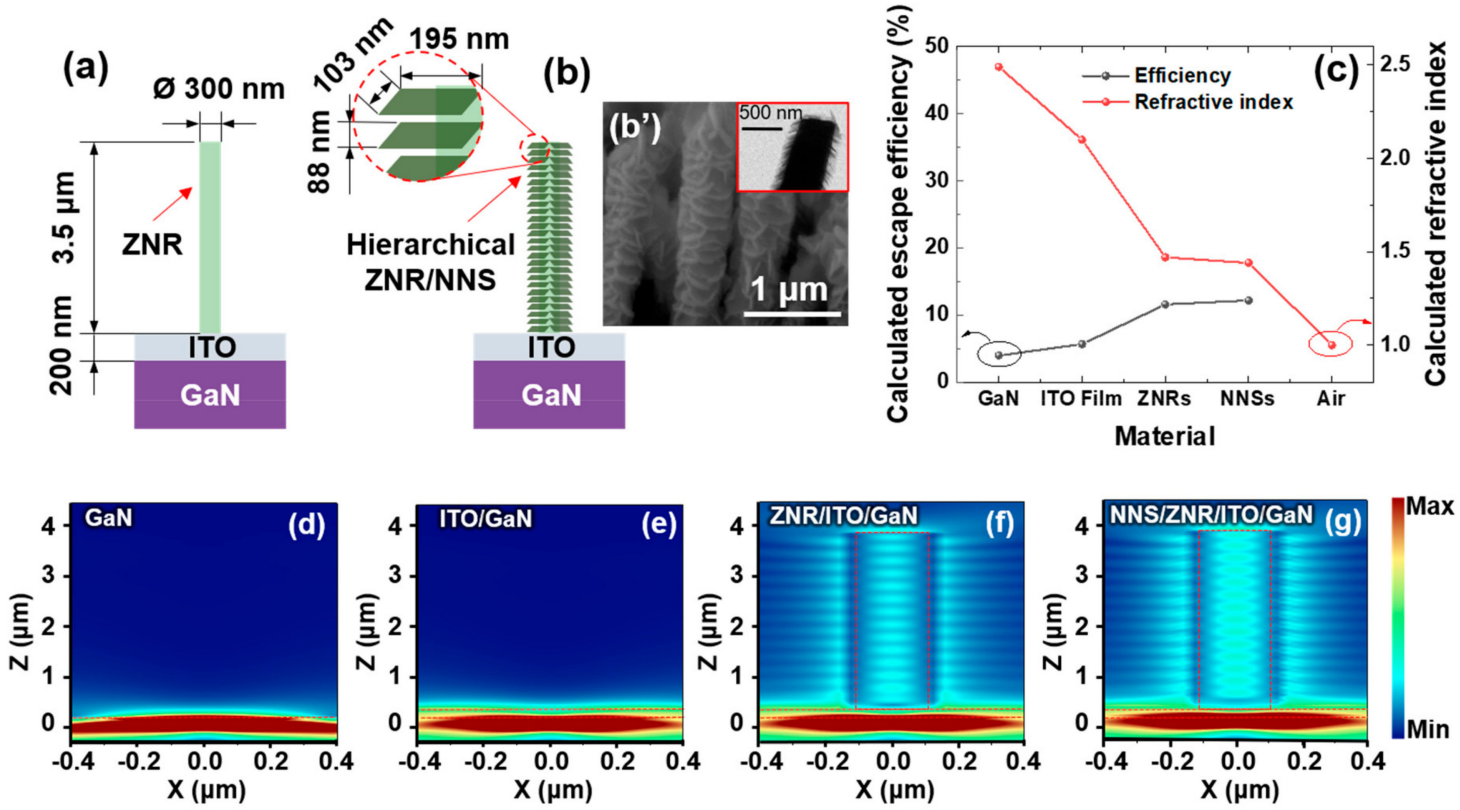

Figure 4. Layouts of the C-emitters with (a) ZNR and (b) hierarchical ZNR/NNS. (b') FESEM and transmission electron microscope (inset) images of the hierarchical ZNR/NNS arrays. (c) Calculated refractive indices and escape efficiencies. $(\mathbf{d}-\mathbf{g})$ Electric field propagation for various C-emitters.

In these simulations, we used the following parameters: ZNR diameter and height of $300 \mathrm{~nm}$ and $3.5 \mu \mathrm{m}$, respectively, based on the corresponding FESEM image (Figure 2a); NNS width and height of $195 \mathrm{~nm}$ and $103 \mathrm{~nm}$, respectively; and consistent interval of $88 \mathrm{~nm}$ between adjacent NNSs based on the FESEM and transmission electron microscope results (Figure $4 b^{\prime}$ ). These structures were simulated on the $200 \mathrm{~nm}$ thick ITO layer deposited on the $430 \mathrm{~nm}$ photonic emitters. The refractive indices of various materials were calculated using EMA [15-17]:

$$
n_{\text {eff }}=\left[n_{\mathrm{ZnO}}^{2} V_{\mathrm{ZnO}}+n_{\mathrm{Air}}^{2}\left(1-V_{\mathrm{ZnO}}\right)\right]^{\frac{1}{2}}
$$

where $n_{\text {eff }}$ is the effective refractive index of the ZNRs; $n_{\mathrm{ZnO}}$ and $\mathrm{n}_{\mathrm{Air}}$ are the refractive indices of $\mathrm{ZnO}$ and air, respectively; and $V_{\mathrm{ZnO}}$ is the volume fraction of $\mathrm{ZnO}$ in the effective medium. The refractive indices and the volume fraction were determined from the FESEM image, as shown in Figure 2a. The average refractive index of the ZNRs was significantly lower than that of the $\mathrm{ZnO}$ film because of the inclusion of air in the effective medium. Therefore, according to EMA, ZNRs have a lower refractive index, even though the refractive index of the $\mathrm{ZnO}$ film was similar to that of the ITO film.

Furthermore, the refractive index of NNSs was lower than that of the ZNRs because the refractive index of $\mathrm{NiO}$ is lower (1.68) than that of the $\mathrm{ZnO}$ film, even though $\mathrm{NiO}$ has the lower air volume, as can be inferred from the FESEM image shown in Figure 2d. Therefore, we can confirm that the calculated refractive indices of the GaN, ITO, ZNRs, NNSs are 2.49, 2.1, 1.47, and 1.44, respectively.

The optimal refractive index of the antireflection layer between the ITO film and air can be computed using the formula: $[33,34]$

$$
n_{1}=\sqrt{n_{0} n_{s}}
$$

The formula yielded a value of 1.449 , which is very similar to the refractive index of the NNSs for a high antireflection effect. 
The escape efficiencies of GaN, ITO, ZNRs, and NNSs (Figure 4c), based on the corresponding calculated refractive indices, can be given as follows [35]:

$$
\frac{P_{\text {escape }}}{P_{\text {source }}} \approx \frac{1}{4} \frac{n_{\text {air }}^{2}}{n_{\text {GaN }}^{2}}
$$

where $n_{G a N}$ is the refractive index of the GaN layer. $P_{\text {escape }}$ and $P_{\text {source }}$ are the escape and source powers of the photonic emitter, respectively. According to the equation, the photonic emitter without the ITO electrode has an escape efficiency of only $4 \%$. This efficiency can be increased to $12.2 \%$ by controlling the refractive index through NNSs growth. However, because this value represents the escape efficiency of photon extraction obtained by considering only the refractive index, it will decrease when considering the efficiency lost through GaN, ITO, and ZNRs. Moreover, the photon efficiency of the device based on various nanostructures is not discussed here, because this calculation considers only layered thin films.

Figure $4 \mathrm{~d}-\mathrm{g}$ illustrate the simulated electric field propagation for the various photonic emitters. As can be inferred from the simulation results shown in Figure $4 \mathrm{~d}$,e, the two emitters have similar propagation images. However, the $\mathrm{C}$-emitter shows a higher field extraction toward the outside compared to the emitter without the ITO electrode because of Fresnel reflection. In the case of Figure 4f, although the ZNR on the C-emitter shows a remarkably higher propagation of electric field toward the outside because of the refractive index control and wave guide effect of $Z N R$, it is limited by the refractive index difference between the ZNR and air and the flat end of the ZNR. This can be explained based on the strong intensity of the electric field inside the ZNR because of interference of the reflected electric field. However, the simulation results of ZNR/NNS on the C-emitter, which are presented in Figure $4 \mathrm{~g}$, shows the stronger electric propagation image than that of ZNR on the C-emitter. This difference can be explained by the fact that the NNSs have a smoother graded effective refractive index change and lower TIR loss from the GaN-based photonic emitter to the outside.

\section{Conclusions}

In conclusion, we successfully grew self-aligned hierarchical ZNR/NNS arrays on a C-emitter through a low-temperature two-step hydrothermal process. Compared to the device with only ZNRs, the device with the hierarchical ZNR/NNS arrays exhibited optimal refractive indices (GaN: 2.49, ITO: 2.1, ZNR: 1.47, NNS: 1.44) and antireflection properties as a result of the graded refractive index and waveguide effect. Therefore, at the injection current of $100 \mathrm{~mA}$, its output power was approximately $17 \%$ higher than that of the C-emitter with ZNRs and twice as high as that of the device without nanostructures; in addition, there was no degradation of electrical properties. The proposed nanostructures can be used to realize various nanotechnology applications, such as photonic emitters, gas sensors, supercapacitors, electrochromic devices, and solar cells.

Author Contributions: W.-S.L., S.-H.K., and K.-K.K. conceived and designed the experiments; H.-J.C. and S.O. conducted the simulation; W.-S.L., S.-H.K., K.-K.K., and H.L. performed the experiments; W.L., S.-H.K., and H.-J.C. analyzed the data; W.-S.L., S.O., K.-G.I. and K.-K.K. wrote the paper. All authors have read and agreed to the published version of the manuscript.

Funding: This research was partly supported by the MSIT(Ministry of Science and ICT), Korea, under the ITRC(Information Technology Research Center) support program(IITP-2020-2019-2018-0-01426) supervised by the IITP(Institute for Information \& Communications Technology Planning \& Evaluation, Korea Institute for Advancement of Technology (KIAT) grant funded by the Korea Government(MOTIE) (P0008458, The Competency Development Program for Industry Specialist), and the work reported in this paper was conducted during the sabbatical year of Korea Polytechnic University in 2019.

Conflicts of Interest: The authors declare no conflict of interest. 


\section{References}

1. Lupan, O.; Pauporté, T.; Viana, B. Low-Voltage UV-Electroluminescence from ZnO-Nanowire Array/p-GaN Light-Emitting Diodes. Adv. Mater. 2010, 22, 3298-3302. [CrossRef] [PubMed]

2. Drobek, M.; Kim, J.-H.; Bechelany, M.; Vallicari, C.; Julbe, A.; Kim, S.S. MOF-Based Membrane Encapsulated ZnO Nanowires for Enhanced Gas Sensor Selectivity. ACS Appl. Mater. Interfaces 2016, 8, 8323-8328. [CrossRef] [PubMed]

3. Li, C.; Han, C.; Zhang, Y.; Zang, Z.; Wang, M.; Tanga, X.-S.; Du, J. Enhanced photoresponse of self-powered perovskite photodetector based on $\mathrm{ZnO}$ nanoparticles decorated $\mathrm{CsPbBr}_{3}$ films. Sol. Energy Mater. Sol. Cells 2017, 172, 341-346. [CrossRef]

4. Huang, M.H.; Mao, S.; Feick, H.; Yan, H.; Wu, Y.; Kind, H.; Weber, E.; Russo, R.; Yang, P. Room-temperature ultraviolet nanowire nanolasers. Science 2001, 292, 1897-1899. [CrossRef]

5. Lee, H.K.; Kim, M.S.; Yu, J.S. Effect of AZO seed layer on electrochemical growth and optical properties of ZnO nanorod arrays on ITO glass. Nanotechnology 2011, 22, 445602. [CrossRef]

6. Özgür,, Ü.; Hofstetter, D.; Morkoç, H. ZnO Devices and Applications: A Review of Current Status and Future Prospects. Proc. IEEE 2010, 98, 1255-1268. [CrossRef]

7. Litton, C.W.; Reynolds, D.C.; Collins, T.C. Zinc Oxide Materials for Electronic and Optoelectronic Device Applications, 1st ed.; John Wiley \& Sons, Ltd.: Chichester, UK, 2011; pp. 29-86.

8. Sun, Y.H.; Chen, L.; Bao, Y.; Zhang, Y.; Wang, J.; Fu, M.; Wu, J.; Ye, D. The Applications of Morphology Controlled $\mathrm{ZnO}$ in Catalysis. Catalysts 2016, 6, 188. [CrossRef]

9. Mirzaei, H.; Darroudi, M. Zinc oxide nanoparticles: Biological synthesis and biomedical applications. Ceram. Int. 2017, 43, 907-914. [CrossRef]

10. Ao, D.; Li, Z.; Fu, Y.Q.; Tang, Y.; Yan, S.; Zu, X.T. Heterostructured NiO/ZnO Nanorod Arrays with Significantly Enhanced $\mathrm{H}_{2} \mathrm{~S}$ Sensing Performance. Nanomaterials 2019, 9, 900. [CrossRef]

11. Oh, S.; Ha, K.; Kang, S.-H.; Yohn, G.-J.; Lee, H.-J.; Park, S.-J.; Kim, K.-K. Self-standing ZnO nanotube/SiO 2 core-shell arrays for high photon extraction efficiency in III-nitride emitter. Nanotechnology 2017, $29,15301$. [CrossRef]

12. Kim, K.-K.; Lee, S.-D.; Kim, H.; Park, J.-C.; Lee, S.-N.; Park, Y.; Park, S.-J.; Kim, S. Enhanced light extraction efficiency of $\mathrm{GaN}$-based light-emitting diodes with $\mathrm{ZnO}$ nanorod arrays grown using aqueous solution. Appl. Phys. Lett. 2009, 94, 071118.

13. Park, Y.J.; Song, H.; Ko, K.B.; Ryu, B.D.; Cuong, T.V.; Hong, C.-H. Nanostructural Effect of ZnO on Light Extraction Efficiency of Near-Ultraviolet Light-Emitting Diodes. J. Nanomater. 2016, 2016, 1-6. [CrossRef]

14. Ong, C.B.; Ng, L.Y.; Mohammad, A. A review of ZnO nanoparticles as solar photocatalysts: Synthesis, mechanisms and applications. Renew. Sustain. Energy Rev. 2018, 81, 536-551. [CrossRef]

15. ElAnzeery, H.; El Daif, O.; Buffiere, M.; Oueslati, S.; Ben Messaoud, K.; Agten, D.; Brammertz, G.; Guindi, R.; Kniknie, B.; Meuris, M.; et al. Refractive index extraction and thickness optimization of $\mathrm{Cu}_{2} \mathrm{ZnSnSe}_{4}$ thin film solar cells. Phys. Status Solidi (A) 2015, 212, 1984-1990. [CrossRef]

16. Xi, J.-Q.; Schubert, M.F.; Kim, J.K.; Schubert, E.F.; Chen, M.; Lin, S.-Y.; Liu, W.; Smart, J.A.; Lončar, M. Optical thin-film materials with low refractive index for broadband elimination of Fresnel reflection. Nat. Photon. 2007, 1, 176-179. [CrossRef]

17. Chao, Y.-C.; Chen, C.-Y.; Lin, C.-A.; Dai, Y.-A.; He, J.-H. Antireflection effect of ZnO nanorod arrays. J. Mater. Chem. 2010, 20, 8134. [CrossRef]

18. Tsai, D.-S.; Lin, C.-A.; Lien, W.-C.; Chang, H.-C.; Wang, Y.-L.; He, J.-H. Ultra-High-Responsivity Broadband Detection of Si Metal-Semiconductor-Metal Schottky Photodetectors Improved by ZnO Nanorod Arrays. ACS Nano 2011, 5, 7748-7753. [CrossRef]

19. Lei, P.-H.; Yang, C.-D.; Huang, P.-C.; Yeh, S.-J. Enhancement of Light Extraction Efficiency for InGaN/GaN Light-Emitting Diodes Using Silver Nanoparticle Embedded ZnO Thin Films. Micromachines 2019, 10, 239. [CrossRef]

20. Leem, Y.-C.; Seo, O.; Jo, Y.-R.; Kim, J.H.; Chun, J.; Kim, B.-J.; Noh, D.Y.; Lim, W.; Kim, Y.-I.; Park, S.-J. Titanium oxide nanotube arrays for high light extraction efficiency of GaN-based vertical light-emitting diodes. Nanoscale 2016, 8, 10138-10144. [CrossRef] 
21. Mao, P.; Mahapatra, A.K.; Chen, J.; Chen, M.; Wang, G.; Han, M. Fabrication of Polystyrene/ZnO Micronano Hierarchical Structure Applied for Light Extraction of Light-Emitting Devices. ACS Appl. Mater. Interfaces 2015, 7, 19179-19188. [CrossRef]

22. Ho, C.-H.; Hsiao, Y.-H.; Lien, D.-H.; Tsai, M.S.; Chang, D.; Lai, K.-Y.; Sun, C.-C.; He, J.-H. Enhanced light-extraction from hierarchical surfaces consisting of $\mathrm{p}-\mathrm{GaN}$ microdomes and $\mathrm{SiO}_{2}$ nanorods for $\mathrm{GaN}_{\text {-based }}$ light-emitting diodes. Appl. Phys. Lett. 2013, 103, 161104. [CrossRef]

23. Leem, Y.; Park, J.S.; Kim, J.H.; Myoung, N.; Yim, S.-Y.; Jeong, S.; Lim, W. Light-Emitting Diodes: Light-Emitting Diodes with Hierarchical and Multifunctional Surface Structures for High Light Extraction and an Antifouling Effect (Small 2/2016). Small 2016, 12, 138. [CrossRef]

24. Park, M.J.; Kim, C.U.; Kang, S.B.; Won, S.H.; Kwak, J.S.; Kim, C.-M.; Choi, K.J. 3D Hierarchical Indium Tin Oxide Nanotrees for Enhancement of Light Extraction in GaN-Based Light-Emitting Diodes. Adv. Opt. Mater. 2016, 5, 1600684. [CrossRef]

25. Zhang, C.; Marvinney, C.E.; Xu, H.; Liu, W.Z.; Wang, C.L.; Zhang, L.X.; Wang, J.; Ma, J.G.; Liu, Y. Enhanced waveguide-type ultraviolet electroluminescence from $\mathrm{ZnO} / \mathrm{MgZnO}$ core/shell nanorod array light-emitting diodes via coupling with Ag nanoparticles localized surface plasmons. Nanoscale 2015, 7, 1073-1080. [CrossRef]

26. Ko, S.H.; Lee, S.; Kang, H.W.; Nam, K.H.; Yeo, J.; Hong, S.J.; Grigoropoulos, C.P.; Sung, H.J. Nanoforest of Hydrothermally Grown Hierarchical ZnO Nanowires for a High Efficiency Dye-Sensitized Solar Cell. Nano Lett. 2011, 11, 666-671. [CrossRef]

27. Ren, X.; Sangle, A.; Zhang, S.; Yuan, S.; Zhao, Y.; Shi, L.; Hoye, R.L.Z.; Cho, S.; Li, D.; MacManus-Driscoll, J.L. Photoelectrochemical water splitting strongly enhanced in fast-grown $\mathrm{ZnO}$ nanotree and nanocluster structures. J. Mater. Chem. A 2016, 4, 10203-10211. [CrossRef]

28. Cai, Y.; Li, X.; Sun, P.; Wang, B.; Liu, F.; Cheng, P.; Du, S.; Lu, G. Ordered ZnO nanorod array film driven by ultrasonic spray pyrolysis and its optical properties. Mater. Lett. 2013, 112, 36-38. [CrossRef]

29. Li, D.; Zhang, Y.; Liu, D.; Yao, S.; Liu, F.; Wang, B.; Sun, P.; Gao, Y.; Chuai, X.; Lu, G. Hierarchical core/shell $\mathrm{ZnO} / \mathrm{NiO}$ nanoheterojunctions synthesized by ultrasonic spray pyrolysis and their gas-sensing performance. CrystEngComm 2016, 18, 8101-8107. [CrossRef]

30. Wang, D.; Zhao, L.; Ma, H.; Zhang, H.; Guo, L.H. Quantative Analysis of Reactive Oxygen Species Photogenerated on Metal Oxide Nanoparticles and Their Bacteria Toxicity: The Role of Superoxide Radicals. Environ. Sci. Technol. 2017, 51, 10137-10145. [CrossRef]

31. Raut, H.; Ganesh, V.A.; Nair, A.S.; Ramakrishna, S. Anti-reflective coatings: A critical, in-depth review. Energy Environ. Sci. 2011, 4, 3779. [CrossRef]

32. Cho, C.-Y.; Kim, N.-Y.; Kang, J.-W.; Leem, Y.-C.; Hong, S.-H.; Lim, W.; Kim, S.-T.; Park, S.-J. Improved Light Extraction Efficiency in Blue Light-Emitting Diodes by $\mathrm{SiO}_{2}-$ Coated ZnO Nanorod Arrays. Appl. Phys. Express 2013, 6, 042102. [CrossRef]

33. Park, J.; Shin, D.S.; Kim, D.-H. Enhancement of light extraction in GaN-based light-emitting diodes by $\mathrm{Al}_{2} \mathrm{O}_{3}$-coated $\mathrm{ZnO}$ nanorod arrays. J. Alloy. Compd. 2014, 611, 157-160. [CrossRef]

34. Moreno, I.; Araiza, J.D.J.; Avendaño-Alejo, M. Thin-film spatial filters. Opt. Lett. 2005, 30, 914. [CrossRef] [PubMed]

35. Sun, W.; Shatalov, M.; Hu, X.; Yang, J.; Lunev, A.; Bilenko, Y.; Shur, M.S.; Gaska, R. Milliwatt Power 245 nm Deep Ultraviolet Light-Emitting Diodes; Institute of Electrical and Electronics Engineers (IEEE): Piscataway, NJ, USA, 2009; pp. 109-110.

(C) 2020 by the authors. Licensee MDPI, Basel, Switzerland. This article is an open access article distributed under the terms and conditions of the Creative Commons Attribution (CC BY) license (http://creativecommons.org/licenses/by/4.0/). 